\title{
Replacement of NCTC 4175, the Current Type Strain of Proteus vulgaris, with ATCC 29905 Request for an Opinion
}

\author{
DON J. BRENNER, ${ }^{1 *}$ FRANCES W. HICKMAN-BRENNER, ${ }^{2}$ BARRY HOLMES ${ }^{3}$ P. M. HAWKEY, ${ }^{4}$ \\ JOHN L. PENNER, ${ }^{5}$ PATRICK A. D. GRIMONT, ${ }^{6}$ AND CAROLINE M. O'HARA ${ }^{7}$ \\ Emerging Bacterial and Mycotic Diseases Branch ${ }^{1}$ and Foodborne and Diarrheal Diseases Branch, ${ }^{2}$ Division of \\ Bacterial and Mycotic Diseases, and Nosocomial Pathogens Laboratory Branch, Hospital Infections Program, ${ }^{7}$ \\ National Center for Infectious Diseases, Centers for Disease Control and Prevention, Atlanta, \\ Georgia 30333; National Collection of Type Cultures, Central Public Health Laboratory, \\ London, ${ }^{3}$ and Department of Microbiology, University of Leeds, Leeds, ${ }^{4}$ England; \\ Department of Medical Microbiology, Banting Institute, University of Toronto, \\ Toronto, Ontario, Canadas; and Unité des Entérobactéries, \\ Institut Pasteur, Paris, France ${ }^{6}$
}

\begin{abstract}
The current type strain of Proteus vulgaris, NCTC 4175 (= ATCC 13315), differs substantially from typical strains of this species both biochemically and chemotaxonomically. DNA relatedness studies revealed that strains previously classified as $\boldsymbol{P}$. vulgaris belong to six genomospecies. One of these genomospecies contains strains that are negative in indole, salicin, and esculin reactions (biogroup 1) and has been named Proteus penneri. A second genomospecies, which is most frequently isolated from human urine, contains typical $P$. vulgaris strains that are positive in indole, salicin, and esculin reactions (biogroup 2). The members of the remaining four genomospecies are indole positive and negative in salicin and esculin reactions (biogroup 3). Of 36 biogroup 3 strains studied, only strain NCTC $4175^{\mathrm{T}}(\mathrm{T}=$ type strain) and one other strain, CDC 1732-80, belong to genomospecies 3. To retain NCTC 4175 as the type strain of $P$. vulgaris would restrict this species to these two strains, whose origins are unknown. This would mean that hundreds of strains for which the description of $P$. vulgaris was written and which have been representatives of this species for the past 50 years would have to be renamed as members of a new species. To prevent this confusion, we request that biogroup 2 reference strain ATCC 29905 (= CDC PR1) replace NCTC 4175 as the type strain of $P$. vulgaris.
\end{abstract}

The genus Proteus was first recognized and named by Hauser in 1885 (8), who described two species, Proteus vulgaris and Proteus mirabilis. Descriptions of these species acceptable to modern taxonomists were not published until 1943 (13), and an acceptable description of the genus was not published until $1974(10)$.

The type strain of $P$. vulgaris is strain NCTC 4175 (= ATCC 13315); the source of this strain is not known, but it originated in the Pribram Collection in Vienna in 1933 (1). This strain was one of several strains recommended in 1958 as neotype cultures of type species of genera in the Enterobacteriaceae by an ad hoc commission appointed by the Enterobacteriaceae Subcommittee (7). In the following year, the Editorial Board of the International Bulletin of Bacteriological Nomenclature and Taxonomy (consisting of R. E. Buchanan, S. T. Cowan, and W. A. Clark) published a preliminary statement summarizing the prior action of the Enterobacteriaceae Subcommittee and submitted the recommendations to the Judicial Commission for final action (3). In Opinion 26, rendered in 1963, all of the recommended neotype strains, including $P$. vulgaris NCTC 4175 , were approved by the Judicial Commission (5).

There is no written indication of why strain NCTC 4175 was proposed as the neotype strain of $P$. vulgaris. All of the neotype strains chosen were in the National Collection of Type Cultures. It is likely that strain NCTC $4175^{\mathrm{T}}$ ( $\mathrm{T}=$ type strain) was

* Corresponding author. Mailing address: Centers for Disease Control and Prevention, Mailstop D11, Atlanta, GA 30333. Phone: (404) 639-2841. Fax: (404) 639-3970. Electronic mail address: DJB3@ CIDDBD2.EM.CDC.GOV. chosen because it was the oldest documented strain in that collection. There was no indication of the biochemical characteristics of this strain or whether it was recharacterized before it was chosen.

The first comprehensive numerical taxonomic study of the genus Proteus was done by McKell and Jones in 1976 (11). In this study, $P$. vulgaris NCTC $4175^{\mathrm{T}}$ was clearly atypical and fell outside the two $P$. vulgaris subclusters, which included 22 strains.

Twelve strains previously identified as $P$. vulgaris strains were included in a DNA relatedness study performed by Brenner et al. (2). These strains fell into two hybridization groups. Unfortunately, the type strain was not included in this study. Hickman et al. subsequently divided $P$. vulgaris sensu lato into three biogroups on the basis of the results of biochemical reactions for indole, salicin, and esculin (9). The members of biogroup 1 , which corresponded to the second hybridization group of Brenner et al. (2), are negative in these three tests and were described as members of a new species, Proteus penneri (9). Biogroup 2 strains gave positive reactions in all three tests, and biogroup 3 strains were indole positive and negative in salicin and esculin reactions (9). Strain NCTC $4175^{\mathrm{T}}$ is a biogroup 3 strain.

Costas et al. used computerized analysis of electrophoretic protein patterns to identify and type $P$. penneri and $P$. vulgaris biogroups 2 and $3(6)$. On the basis of the results of an analysis of partial protein patterns, these authors concluded that $P$. penneri and most $P$. vulgaris biogroup 2 strains could be distinguished easily. The biogroup 3 strains belonged to two subclusters, and when total protein patterns were analyzed, each of these subclusters proved to be heterogeneous. Strain NCTC 
$4175^{\mathrm{T}}$ clustered closely with only one strain, CDC $1732-80$, in phenon 7 of subcluster 3 a.

DNA relatedness studies performed with $36 P$. vulgaris biogroup 3 strains obtained from our laboratories confirmed the heterogeneity of the strains belonging to this biogroup (12). Four hybridization groups, representing new genomospecies, were identified. Genomospecies 5 (18 strains) and 6 (11 strains) could not be distinguished phenotypically; 91 to $100 \%$ of the strains of both of these genomospecics were positive in tests for L-tartrate (Jordan's test) and corn oil lipase activity, and 0 to $6 \%$ of the strains were positive in L-rhamnose tests. All of the genomospecies 5 strains and $55 \%$ of the genomospecies 6 strains were positive for DNase activity. Genomospecies 4 (five strains) could be differentiated from genomospecies 5 and 6 on the basis of the results of the L-rhamnose reaction (all of the genomospecies 4 strains were positive). Strain NCTC $4175^{\mathrm{T}}\left(=\right.$ ATCC $\left.13315^{\mathrm{T}}\right)$ was a member of genomospecies 3, along with only one other strain, CDC 1732-80. Genomospecies 3 could be differentiated from the other genomospecies on the basis of its uniformly negative reactions in L-rhamnose, tartrate, corn oil lipase, and DNase tests.

To retain NCTC 4175 as the type strain of $P$. vulgaris would restrict this species to two strains, whose sources are not known. Hundreds of strains previously considered typical members of $P$. vulgaris would have to be placed in a new species. These are the strains for which the description of $P$. vulgaris was written and which have represented the species for approximately 50 years. The entire literature on $P$. vulgaris, including the role of this organism in human urinary tract and other infections, would refer to strains that were no longer in this species, and this would no doubt cause substantial confusion among clinical microbiologists, microbial geneticists, and other microbiologists.

We are aware that atypical characteristics are not a sufficient basis for changing a type strain. In this case, the neotype strain, which was designated approximately 60 years after $P$. vulgaris was discovered, does not represent the vast majority of strains on which the species description is based. We request that NCTC 4175 be replaced as the type strain of $P$. vulgaris on the basis of the following portions of the International Code of Nomenclature of Bacteria (14):

(i) Retaining NCTC 4175 as the neotype strain violates Principle 1 in that it causes nomenclatural instability and would result in a name that may cause error or confusion.

(ii) Replacing NCTC 4175 is in accordance with Principle 9 in that additional taxonomic studies have indicated that the original designation was in error, since a strain that is genomically different from the vast majority of strains assigned to the species was designated the neotype strain.

(iii) In violation of Rule $18 \mathrm{c}$, neither a description nor a reference to an effectively published description was given when NCTC 4175 was proposed as the neotype strain.

(iv) NCTC 4175 became unsuitable as the neotype strain of $P$. vulgaris when it was determined that genomically this strain differs from the vast majority of strains assigned to the species. Therefore, in accordance with Rule $18 \mathrm{~g}$, we refer the matter to the Judicial Commission with the request that it replace NCTC 4175 with the strain proposed below.
In the 1958 edition of the International Code of Nomenclature of Bacteria and Viruses, under Rule 9d, a neotype culture is defined as "one which has been accepted by international agreement to replace a type culture which is no longer in existence. It should agree with the diagnosis given by the original describer and should be recommended by those workers familiar with the species, and their agreed recommendation approved by the Judicial Commission" (4). Although this rule is not included in the most recent edition of the International Code of Nomenclature of Bacteria (14), it has not been contradicted. As workers familiar with $P$. vulgaris, we are in agreement that NCTC 4175 is not appropriate to represent $P$. vulgaris for the reasons stated above. Therefore, we request that the Judicial Commission approve our proposal that strain ATCC 29905 (= CDC PR1) should replace NCTC 4175 as the type strain of $P$. vulgaris. ATCC 29905 has served as the DNA relatedness reference strain of $P$. vulgaris since $1978(10)$ and has been available from the American Type Culture Collection since 1980 . It has been fully characterized biochemically and has been shown to be a typical biogroup 2 strain of $P$. vulgaris by workers at the Centers for Disease Control and Prevention and at the American Type Culture Collection.

\section{REFERENCES}

1. Anonymous. 1994. Catalogue of the National Collection of Type Cultures (NCTC), 7th ed., p. 79. Public Health Laboratory Service, London.

2. Brenner, D. J., J. J. Farmer III, G. R. Fanning, A. G. Steigerwalt, P. Klykken, H. G. Wathen, F. W. Hickman, and W. H. Ewing. 1978. Deoxyribonucleic acid relatedness of Proteus and Providencia species. Int. J. Syst. Bacteriol. 28:269-282.

3. Buchanan, R. E., S. T. Cowan, and W. A. Clark (ed.). 1959. Designation of neotype cultures of the type species of certain genera of the family Enterobacteriaceae: Salmonella, Shigella, Arizona, Escherichia, Citrobacter, and Proteus. Preliminary statement. Int. Bull. Bacteriol. Nomencl. Taxon. 9:105107.

4. Buchanan, R. E., S. T. Cowan, T. Wiken, and W. A. Clark (ed.). 1958. International code of nomenclature of bacteria and viruses. Iowa State College Press, Ames.

5. Buchanan, R. E., H. P. R. Seeliger, and W. A. Clark (ed.). 1963. Opinion 26. Designation of neotype strains (cultures) of type species of the bacterial genera Salmonella, Shigella, Arizona, Escherichia, Citrobacter, and Proteus of the family Enterobacteriaceae. Int. Bull. Bacteriol, Nomencl. Taxon. 13:3536.

6. Costas, M., B. Holmes, K. A. Frith, C. Riddle, and P. M. Hawkey. 1993. Identification and typing of Proteus penneri and Proteus vulgaris biogroups 2 and 3, from clinical sources, by computerized analysis of electrophoretic protein patterns. J. Appl. Bacteriol. 75:489-498.

7. Ewing, W. H. 1958. Minutes of the International Enterobacteriaceae Subcommittee meetings, VII International Congress of Microbiology, Stockholm, August 1958. Int. Bull. Bacteriol. Nomencl. Taxon. 8:173-179.

8. Hauser, G. 1885. Über Fäulnissbacterien und deren Beziehungen zur Septicämie. Ein Beitrag zur Morphologie der Spaltpilze, p. 12. Vogel, Leipzig, Germany.

9. Hickman, F. W., A. G. Steigerwalt, J. J. Farmer III, and D. J. Brenner. 1982. Identification of Proteus penneri sp. nov., formerly known as Proteus vulgaris indole negative or as Proteus vulgaris biogroup 1. J. Clin. Microbiol. 15:10971102.

10. Lautrop, H. 1974. Genus X. Proteus, p. 327-330. In R. E. Buchanan and N. E. Gibbons (ed.), Bergey's manual of determinative bacteriology, 8th ed. Williams \& Wilkins, Baltimore.

11. McKell, J., and D. Jones. 1976. A numerical taxonomic study of the ProteusProvidence bacteria. J. Appl. Bacteriol. 41:143-161.

12. O'Hara, C., F. W. Hickman-Brenner, A. G. Steigerwalt, B. C. Hill, F. C. Tenover, M. Costas, B. Holmes, P. A. D. Grimont, P. M. Hawkey, J. L. Penner, J. M. Miller, and D. J. Brenner. Unpublished data.

13. Rustigian, R., and C. A. Stuart. 1943. Taxonomic relationships in the genus Proteus. Proc. Soc. Exp. Biol. Med. 53:241-243.

14. Sneath, P. H. A. (ed.). 1992. International code of nomenclature of bacteria. 1990 revision. American Society for Microbiology, Washington, D.C. 